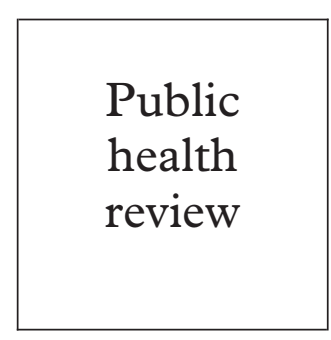

\title{
Increasing prevalence of genital herpes in developing countries: implications for heterosexual HIV transmission and STI control programmes
}

\author{
Nigel O’Farrell
}

Background: The recognition that sexually transmitted infections (STI) facilitate HIV transmission among heterosexuals has led to a rejuvenated focus on improving STI control as a component of HIV prevention programmes in developing countries. While efforts so far have focused mainly on all STI, there is increasing evidence that genital ulcers facilitate a considerable proportion of HIV transmission among heterosexuals and that this effect has been underestimated. This paper focuses on the epidemiology of genital herpes in developing countries past and present.

Objectives: To review the scientific literature about the epidemiology of genital herpes in developing countries and discuss the implications of the findings for STI control and HIV prevention programmes.

Search methodology: A Medline search for June 1966 to August 1999 using the keywords, genital herpes, STD and developing countries, and genital ulcers in $\mathrm{MeSH}$ and free text. Abstract books from recent international AIDS conferences and other international STD conferences were reviewed. The annual reports of the medical officers of heath for Harare 1982-1998 and Durban 1989-1997 were reviewed to detect trends in genital herpes diagnoses.

Findings: Genital herpes, formerly regarded as a minor STI in most developing countries, has now emerged as a leading cause of genital ulceration in many countries where syphilis and chancroid were more prevalent previously. This increased recognition of genital herpes reflects both a change in the pattern of STI epidemiology through a decline in syphilis and chancroid as a response to HIV control programmes and improved techniques for diagnosing herpetic infection. Countries with significant heterosexual HIV epidemics also appear to have rapidly increasing numbers of genital herpes cases.

Conclusions: The emergence of this herpes epidemic must be addressed through innovative strategies that will be viable, sustainable, acceptable, and effective in developing countries. In countries where genital herpes is a significant problem, local adaptation of WHO treatment algorithms should be made. STI service providers should be trained about issues around the transmission of herpes and how best to advise clients about dealing with, and recognising, recurrences. The effectiveness of antiviral treatment for genital herpes should be investigated in core groups at high risk of HIV.

(Sex Transm Inf 1999;75:377-384)

Keywords: genital herpes; genital ulcers; sexually transmitted infections; developing countries; HIV; Africa

\section{Introduction}

The role of sexually transmitted infections (STI), and genital ulcer disease (GUD) in particular, in facilitating heterosexual transmission of HIV in developing countries is well established. ${ }^{1}$ This recognition has led to an increased focus on STI cases to be managed at the primary healthcare level using the syndromic approach. However, although syndromic management was put forward by the World Health Organisation as a strategy for limiting the morbidity of sexually transmitted diseases in developing countries in the early 1980s before HIV became a significant problem, it is clear that further innovative strategies are needed to reduce the global burden of STI.

Numerous studies have identified higher relative risks of HIV infection with GUD than with other STI and STI syndromes. ${ }^{2}$ This risk differential depends upon both the relative frequencies of the various STI syndromes in different populations and the direction of HIV transmission - that is, male to female or female to male. ${ }^{1}$ Population attributable risks of HIV to GUD as high as $69 \%$ among male clients of female sex workers (FSW) in Nairobi ${ }^{3}$ (relative risk (RR) 11.3) and 54\% in STI clinic attenders in India (RR 7.0) are reported. At the individual level, an assessment of the GUD cofactor effect per sexual exposure of HIV transmission determined an increased risk of 10-50 for male to female and 50-300 for female to male. ${ }^{5}$

Most STI strategies and programmes have tended to target STIs overall and have not taken into account the diverse prevalences of the various STI syndromes that occur in different geographical locations. In most countries of east, central, and southern Africa, a much higher incidence of genital ulceration is reported than in west Africa. A similar epidemiological pattern is seen in the spread of HIV 
infection. Although not proved, high rates of GUD may be important in explaining the higher HIV prevalences in east, central, and southern Africa. While the syndromic approach is simple and can be used by healthcare workers at the primary healthcare level, an increased emphasis on GUD specifically is certainly justified in some settings.

Although public health policymakers have recognised improved management of STI as part of HIV control efforts, the significant role that GUD plays in this process has not been emphasised. This is regrettable because the true effect of genital ulcers in enhancing HIV transmission is probably much greater than that demonstrated so far for a number of reasons, including the following:

(1) Lack of availability of tests for acute GUD. Reliable tests for the most common causes of GUD are expensive other than the rapid plasma reagin (RPR) and venereal diseases research laboratory (VDRL) nonspecific tests for syphilis.

(2) Poor sensitivity of tests for acute GUD: the sensitivity of tests for culture for herpes simplex virus (HSV) and Haemophilus ducreyi may be only $50 \%$ or less. Primary syphilis may be missed by relying on RPR and VDRL tests alone. Also, it may be that the low reported prevalence of HSV in microbiological studies in Africa reflects the order in which swabs were taken from ulcers. Swabs are usually taken in the order of the most likely clinical diagnosis to maximise positive diagnoses. If $\mathrm{HSV}$ was thought to be uncommon, swabs for $H$ ducreyi and syphilis would be taken first followed by those for HSV. The likelihood of obtaining material from ulcers that would grow herpes simplex by the time a third swab was taken would be expected to be low.

(3) Unrecognised complications of GUDfor example, healed ulcers, may cause tissue contraction and thinning of genital mucosa, particularly in uncircumcised men, which may be susceptible to tears and abrasions if subjected to trauma, and thereby facilitate acquisition of HIV. These complications may not be attributed to an episode of genital ulceration.

(4) Delay in presentation with GUD to a healthcare facility. For example, among STD clinic attenders with GUD in Durban, 34\% of men and $36 \%$ of women delayed for $>14$ days after the start of ulcer symptoms before presentation and $9 \%$ of the men and $13 \%$ of the women delayed for more than 30 days. ${ }^{6}$ In patient groups where delayed presentation is common, it is likely that many patients with genital herpes will not present to healthcare settings because signs and symptoms will have resolved in the first week or so. Also, presentation with typical herpetic vesicles may be uncommon - none of the Durban patients had herpetic vesicles. Patients with genital herpes are therefore also likely to be underrepresented in microbiological surveys for this reason.

(5) Lack of recognition of small and/or asymptomatic ulcers as an STI problem-for example, mild episodes of genital herpes. The part that asymptomatic viral shedding plays in HSV transmission has been underestimated in the past. At the population level, the risk of HIV transmission attributable to HSV through asymptomatic shedding could be very significant.

(6) Other factors that could reflect an underestimation of the true effect of GUD on HIV transmission also apply to STIs in general and include: (a) underestimation of self reported STI in STI clinic populationspatients may not report previous STI because of stigma or, in repeat attenders, a fear of derogatory comments from healthcare providers who have advised them previously about safer sex; (b) lack of temporal sequence of disease acquisition-in cross sectional studies, subjects identified with genital ulcers and in the process of HIV seroconversion may be in the HIV window period at the time of testing.

All of these points are relevant to genital herpes and explain why the condition has been underestimated. Despite its recognition as a possible risk factor for HIV infection in heterosexual populations at high risk of HIV in sub-Saharan Africa some time ago, ${ }^{8-10}$ herpes is only now starting to receive more attention in developing countries because of its possible importance in facilitating HIV transmission.

\section{SEARCH STRATEGY}

1A Medline search was carried out for June 1966 to August 1999 using the keywords genital herpes, STD and developing countries, and genital ulcers in $\mathrm{MeSH}$ and free text. Abstract books from recent international AIDS conferences and other international STD conferences were reviewed. The annual reports of the medical officers of heath for Harare 1982-1998 and Durban 1989-1997, two areas with high HIV prevalences $(>30 \%$ of antenatal clinic (ANC) attenders HIV positive) were reviewed to detect trends in genital herpes cases.

\section{HSV in developing countries: the past}

Most early studies of GUD in developing countries identified syphilis and chancroid as the main causes. There are few references to genital herpes until studies investigating the aetiology of GUD in the early 1980s. Clinical cases of genital herpes even merited publication as case reports in the 1970 s. $^{11}$

In Asia, chancroid was usually the most prevalent cause of GUD in most early studies. However, by the early 1980s genital herpes accounted for $17 \%$ of genital ulcers ${ }^{12}$ and $11 \%$ of purulent genital lesions in Singapore, ${ }^{13}$ and $12 \%$ in Bangkok. ${ }^{14}$ In Madurai India, syphilis accounted for $30 \%$ of STD cases followed by chancroid $15 \%$ while genital herpes was recorded under other STI. ${ }^{15}$

In Africa most of the studies undertaken during the 1980s investigating the microbial aetiology of genital ulcers found low prevalences of genital herpes. Among men the prevalence of HSV detected by culture was 3\% in Carletonville, ${ }^{16} 4 \%$ in Nairobi, ${ }^{17} 4 \%$ in Pretoria, ${ }^{18} 7-10 \%$ in Durban, ${ }^{6}{ }^{19} 9 \%$ in Johannesburg $^{20}$; and among men and women, $6 \%$ in the Gambia ${ }^{21}$ and $12 \%$ in Swaziland ${ }^{22}$; and in women, $2 \%$ in Nairobi, ${ }^{23} 6 \%$ in Johannesburg, ${ }^{24}$ and $18 \%$ in Durban. ${ }^{7}$ 
Although diagnostic facilities for herpes have not been available routinely, some health departments have kept a separate tally of cases of genital herpes based on clinical diagnoses. Among STI attenders at three municipal clinics in Harare, Zimbabwe, genital herpes accounted for $6.1 \%$ of all STI cases in $1982 .{ }^{25}$ When genital herpes was introduced into routine reporting at the city health STI clinic in Durban in 1989, 2806 cases were diagnosed whereas, previously, genital herpes was classified under non-STIs. ${ }^{26}$ Although HIV related immunodeficiency may be a factor in HSV recurrences, the prevalence of HIV in both Harare and Durban at these times was low.

Results from the limited numbers of studies undertaking HSV-2 serology indicate significant prevalences among sexually active individuals in diverse locations- $96 \%$ in sex workers in Dakar, Senegal (1985), $71 \%$ in adults in Brazzaville, Congo (1982), $51 \%$ in hospital workers in Rwanda (1985), and $41 \%$ in adults in Kinshasa, Zaire (1985). ${ }^{27}$ Although these studies used older serological tests, which are recognised as having limited diagnostic value because of their lack of sensitivity, these levels are comparable with, if not higher than, similar groups in developing countries throughout the world. ${ }^{28}$

A notable pointer to the underdiagnosis of HSV in Africa is perhaps reflected in the study by Hazlett et $a l^{29}$ who showed that even in the early 1980 s, $13 \%$ of men with genital ulcers with clinical appearances diagnostic of chancroid had proved genital herpes.

HSV in developing countries: the present The spread of HIV since the 1980s and subsequent behaviour change have resulted in significant alterations in STI epidemic patterns in which the relative importance of genital herpes has increased in many countries. In Asia, these changes may reflect increased condom use and a reduction in sexual contact with sex workers. The most noticeable example of this phenomenon has been in Thailand where the incidence of chancroid and syphilis was reduced from nearly 39000 and 11855 cases in 1987 to 1990 and 3645 respectively in $1993 .^{30}$ In Singapore, genital herpes $(72 \%)$ is now by far the most common cause of GUD followed by chancroid $(16 \%)$ and syphilis (3\%). ${ }^{31}$ In Kuala Lumpur, Malaysia, HSV-2 was identified by culture and immunofluorescence in $19 \%$ and $H$ ducreyi in $9 \%$ of STD clinic attenders with GUD. ${ }^{32}$ A survey of five STD clinics in Papua New Guinea identified genital herpes, diagnosed clinically, as the most common cause of GUD. ${ }^{33}$

Changes in the epidemiological patterns of GUD have been less pronounced in Africa compared with Asia. In Africa, condom use is still very low in many countries and commercial sex encounters may not be as readily identified as high risk situations for HIV transmission compared with Asia. However, like Asia, many areas in Africa have shown increasing prevalences of genital herpes. This may reflect not only a global increase in the numbers of cases but also a greater number of HIV positive people in populations sampled. In a population of HIV positive Africans living in London followed up for a mean of 14 months, $42 \%$ developed genital herpetic lesions. ${ }^{34}$

The first microbiological study in which a significant prevalence of HSV was detected in Africa was in Rwanda where prevalences of $18 \%$ in men and $20 \%$ in women were detected by culture among patients with GUD of whom $43 \%$ of the men and $77 \%$ of the women were HIV positive. ${ }^{35}$ Studies elsewhere using viral culture, in men and women, detected HSV prevalences of $48 \%$ in Kampala, Uganda ${ }^{36}$ (65\% HIV positive) and $24 \%$ in Botswana ${ }^{37}$ ( $41 \%$ HIV positive). There are few reliable data about trends in chancroid infections in Africa although in Zimbabwe, one of the worst affected countries with HIV, the numbers of cases diagnosed clinically at the genitourinary centre in Harare decreased from 2972 in 1990 to 430 in $1998 .^{38}{ }^{39}$ While this decrease is not as dramatic as in Thailand, these data suggest that STI interventions are achieving a significant impact although any clinical reports of disease specific diagnoses in Africa must be viewed with caution.

Increased access and availability of HSV-2 antibody tests have confirmed significant prevalences of HSV infection in Africa. In rural populations in Africa sampled randomly, the prevalence of HSV-2 antibodies was $75 \%$ in women $>25$ years and $60 \%$ in men $>30$ years in Mwanza, Tanzania ${ }^{40}$ and $68 \%$ overall in Masaka, Uganda. ${ }^{41}$ High rates (59\%) are also reported in commercial sex workers in Nigeria. ${ }^{42}$ Among young men recruited into the armed forces in northern Thailand, the HSV-2 antibody prevalence was $41 \% .^{43}$ These levels are higher than those in the United States, ${ }^{44}$ where, since the $1970 \mathrm{~s}$, the prevalence of HSV-2 in the general population increased by $30 \%$ to levels of $26 \%$ in women and $18 \%$ in men in 1988-94.

Genital herpes is also a significant problem in central and South America. HSV-2 type specific antibodies were detected in $61 \%$ of commercial sex workers in Mexico City, ${ }^{45} 53 \%$ of STI patients in Campinas City, Brazil ${ }^{46}$ and $39 \%$ of women selected randomly in Costa Rica. ${ }^{47}$

\section{TESTING WITH MULTIPLEX PCR}

An important development in the 1990s has been the introduction of a multiplex polymerase chain reaction (PCR) assay for genital ulcers. This has enabled an assessment to be made for genital herpes in situations that do not have routine access to viral culture. Results from these studies are shown in table 1 and demonstrate significant prevalences of genital herpes in all the populations studied. The highest prevalence was reported in STI clinic attenders with genital ulcers in northern Thailand where $31 / 38(82 \%)$ were positive for HSV from a population in whom $46 \%$ were HIV positive. ${ }^{53}$ In Pune, India, genital herpes was the most frequent infection $(26 \%)$ followed by chancroid (23\%) and syphilis $(10 \%) .^{52}$ In Africa, $43 \%$ of subjects with genital ulcers in the Rakai mass treatment trial ${ }^{49}$ and $26 \%$ in 
Table 1 Genital herpes and HIV status in subjects with genital ulcers using a multiplex polymerase chain reaction (M-PCR) assay

\begin{tabular}{|c|c|c|c|}
\hline & Study subjects & $H S V(\%)$ & $H I V(\%)$ \\
\hline \multicolumn{4}{|l|}{ Africa } \\
\hline Maseru, Lesotho ${ }^{48}$ & 69 male STI, 36 female STI & 26 & 36 \\
\hline Rakai, Uganda ${ }^{49}$ & 207 men and women & 43 & NG \\
\hline Carletonville, South Africa ${ }^{50}$ & 233 male and female STI & 13 & 56 \\
\hline Capetown, South Africa ${ }^{50}$ & 213 male and female STI & 22 & 14 \\
\hline Abidjan, Ivory Coast ${ }^{51}$ & 94 female sex workers & 27 & NG \\
\hline \multicolumn{4}{|l|}{ Asia } \\
\hline Pune, India ${ }^{52}$ & 277 male STI, 25 female STI & 26 & 22 \\
\hline Chiang Mai, Thailand ${ }^{53}$ & 8 male STI, 30 female sex workers & 82 & 46 \\
\hline Phonm Penh, Cambodia ${ }^{54}$ & $\begin{array}{l}17 \text { female sex workers/men/ } \\
\text { reproductive health clinic clients }\end{array}$ & 79 & NG \\
\hline \multicolumn{4}{|l|}{ Caribbean } \\
\hline Kingston, Jamaica ${ }^{55}$ & 252 male STI, 52 female STI & 52 & 22 \\
\hline
\end{tabular}

$\mathrm{NG}=$ not given .

Maseru, Lesotho, were identified with genital herpes. ${ }^{48}$

Initially, it was thought that, with the introduction of PCR, the numbers of cases with no known cause, previously around $20-30 \%$ in most studies, would be low. However, while the proportion of unidentified ulcers was only $6 \%$ in Lesotho, ${ }^{48}$ no cause was identified for $51 \%$ in Rakai, Uganda. ${ }^{49}$ Rompalo and colleagues have discussed different definitions for genital ulcers and found that different communities have different perceptions about the significance of genital ulcers. ${ }^{56}$

HSV AS A RISK FACTOR FOR HIV

As tests for herpes have become more widely available, so the evidence implicating HSV in HIV transmission has increased and has been discussed in recent review articles. ${ }^{157}$ More recent studies have added further evidence supporting the association between HSV-2 antibodies and HIV. Significant correlations between HIV and HSV-2 specific antibodies were found in Zimbabwe among male factory workers (odds ratio (OR) 8.0), ${ }^{58}$ in Tanzanian STI clinic attenders (OR 2.5),,$^{59}$ in Thai military recruits with a history of ulcers in the past 3 years (prevalence ratio (PR) 14.4) and in those without a history of ulcers (PR 2.6), ${ }^{60}$ and in STI patients in Lesotho (PR 1.9). ${ }^{48}$ In the population based study in Masaka, Uganda, the initial phase showed high levels of HSV seropositivity $-57 \%$ in men and $74 \%$ in women but an OR for association with HIV infection of only $1.2 .^{61}$ However, in a later phase of the study the RR of HSV incidence was 3.7 in HIV positive cases versus HIV negative and HIV prevalence was strongly associated with HSV-2. ${ }^{41}$ While this study did not examine the relation between HIV incidence and HSV-2 incidence, the population risk of HIV attributable to genital herpes is likely to be considerable given that recurrent episodes of genital ulceration are common.

\section{Trends in HSV}

Until recently most diagnoses of herpes in developing countries were made on clinical grounds and were therefore open to observer error. However, in areas where longitudinal data are available, a steady rise in the number of genital herpes cases has been recorded. In Singapore, genital herpes cases increased threefold among STI clinic attenders between
1977 and $1993 .^{62}$ In Chandigardh, India, a fourfold increase in genital herpes was observed in STD clinic attenders from 1977 to $1990 .{ }^{63}$ In Harare, genital herpes diagnosed clinically increased from $6.1 \%$ of all new STI diagnoses in $1982^{25}$ to $462 / 4822(9.6 \%)$ in $1993^{64}$ and $736 / 7167(10.3 \%)$ in $1997 . .^{65}$ In Durban, clinical genital herpes cases/new STI diagnoses increased from 2806/41 126 (6.8\%) in $1989^{26}$ to $5664 / 53057(10.7 \%)$ in $1994,{ }^{66}$ and to $7865 / 72363(10.9 \%)$ in $1997 .{ }^{67}$ A more dramatic increase can be observed in the increased prevalence of HSV detected by culture in men with GUD in Durban from 7\% in $1984^{19}$ to $10 \%$ in $1989^{6}$ and $40 \%$ in $1998 .{ }^{68}$ It is not known whether these raised HSV rates are just in HIV positive cases or also in HIV negative cases (which might imply an overall increase in HSV transmission secondary to the HIV epidemic). The overall prevalence of HIV in the Durban/KwaZulu/Natal region increased from $<1 \%$ in 1989 to $32.5 \%$ in $1998 .{ }^{69}$

Elsewhere in South Africa, a significant increase in the prevalence of genital herpes from $3.3 \%$ to $14.4 \%$ was observed over three cross sectional studies involving 200 patients with genital ulcers per round in 1986, 1990, and 1994 in a population of gold miners in Johannesburg. ${ }^{70}$ During the same time the prevalence of HIV in patients with ulcers increased from $<1 \%$ to $>40 \%$. In Rwanda the prevalence of culture confirmed HSV in HIV positive patients with GUD increased from $11 \%$ in $1986-8$ to $21 \%$ in $1990-1992 .^{71}$

In Nigeria, the prevalence of HSV-2 antibodies in female sex workers ranged from $25 \%$ in 1978 in Ibadan $^{72}$ to $59 \%$ in Lagos in $1990 / 1 .^{42}$ In Kinshasa, Zaire, the prevalence of HSV antibodies in selected comparable populations increased from $21 \%$ to $60 \%$ between 1959 and 1985 and in rural areas from $6 \%$ to $32 \% .{ }^{27}$ An exception to this trend of increasing HSV infection was reported in Jamaica where a decrease in the prevalence of genital herpes over time from $17 \%$ in $1982 / 3$ to $7 \%$ in $1990 / 1$ was thought to reflect intense media coverage for genital herpes in $1982 / 3 .{ }^{73}$ However, by 1996, genital herpes, detected by PCR, accounted for $52 \%$ of GUD among STI patients in Kingston. ${ }^{55}$

These studies indicate a significant increasing prevalence of HSV-2 throughout the developing world. It would seem that most countries with high prevalences of HIV also have a considerable public health problem with genital herpes.

\section{Implications of emergence of HSV}

SYNDROMIC MANAGEMENT

In 1985, WHO guidelines set out a simplified genital ulcer protocol that recommended treating ulcerative lesions for syphilis and chancroid and managing multiple superficial lesions with vesicles as genital herpes. ${ }^{74}$ The 1991 protocol also recommended that vesicular lesions or a history of vesicles should be managed as herpes and other ulcers be treated for syphilis or chancroid. ${ }^{75}$ Evaluation of this protocol for correct treatment of syphilis and chancroid in Kigali, Rwanda, found a sensitivity of $99 \%{ }^{76}$ 
However, the sensitivity for genital herpes using diagnostic criteria vesicles or a history of vesicles was only $5 \%$ compared with $48 \%$ for clinical diagnosis. The WHO recommendations for GUD published in 1994 advised treatment for syphilis and chancroid but did not include herpes management in the algorithm although it was acknowledged that an increasing proportion of ulcers were likely to be herpetic where HIV infection was prevalent. ${ }^{77}$ Recently a WHO advisory group has recognised the importance of genital herpes and recommended that subjects with vesicles or small ulcers, with a history of recurrent vesicles, should be managed as if they had genital herpes. ${ }^{78}$

In many areas where genital herpes is now the most frequent cause of GUD, WHO guidelines for GUD have not been accepted. Physicians proud of their clinical acumen are loathe to treat for syphilis and chancroid when herpes presents with classic appearances. Similarly, other STI service providers may be unwilling to give scarce antibacterial drugs for those with a high probability of being infected with herpes rather than syphilis and/or chancroid.

An evaluation of the 1994 WHO algorithm for GUD in a population with significant prevalences of chancroid, syphilis, and genital herpes showed a $63 \%$ overtreatment for syphilis and no patients receiving adequate herpes counselling, clearly an unsatisfactory outcome. ${ }^{79}$ The performance of the GUD algorithm improved with the criteria of small blisters, small ulcers, and a history of recent blisters for a diagnosis of herpes, so that counselling was adequate in $29 \%$ of genital herpes and, although overtreatment for primary syphilis was $57 \%$, correct treatment for other causes of GUD was still $90 \%$.

If clients with genital herpes have recurrences, they may assume that further treatment is indicated based on their experience of receiving an injection and a course of antibiotics at their previous attendance if managed under the 1994 protocol. This message will then be reinforced again repeatedly at subsequent visits. Whether this strategy is effective at the community level is unknown. While cases of syphilis and chancroid will receive effective treatment, the incidence of repeat syphilis and chancroid infections will be very low compared with the numbers of herpes recurrences. Also, if patients do not comply with extended courses of erythromycin, the usual drug of choice for chancroid, and yet still find that their ulcer is cured, they may lose faith in the STD service offered. Unnecessary overtreatment could alter treatment seeking behaviour at the community level leading to subsequent delays in presentation of syphilis and chancroid.

Parallels can be drawn with the WHO algorithm for vaginal discharge used as a predictor of cervical infection with gonorrhoea or chlamydia in which positive predictive values as low as $10 \%$ are difficult to justify on economic grounds. ${ }^{80}$ In those countries where drug expenditure for a single STI syndrome is more than the average healthcare expenditure per annum and drugs are continually in short supply, healthcare workers will be reluctant to overprescribe to the extent required for the current syndromic management approach guidelines to be a successful strategy alone.

A further problematic area in syndromic management of GUD is partner notification. Patients treated for GUD are usually advised that their partners should attend and receive epidemiological treatment. This may be a source of discontent and friction in couples who may assume that their partner has had other sexual partners outside the relationship. Issues about partner notification for contacts of index cases with genital herpes are still uncertain, particularly in areas where multiple causes of GUD are prevalent. Although many patients are infected by asymptomatic partners some of these supposedly asymptomatic infected subjects can be taught to recognise signs and symptoms of genital herpes that have gone unrecognised previously. ${ }^{81}$ While discussion of genital herpes transmission with partners may not be straightforward, the consultation would, at the very least, provide an opportunity both for health education and to reinforce the importance of abstaining from sexual intercourse while genital ulcers are present.

Previous WHO treatment guidelines have not take into account regional variation in GUD epidemiology. While the WHO algorithm has been demonstrated to be cost effective in Rwanda, ${ }^{76}$ in countries with established high prevalences of HSV approaching levels in the west-for example, Thailand, there is a clear justification for genital ulcer algorithms to include genital herpes. Some Asian countries have acknowledged this and made their own adaptations - for example, in the Philippines, where syphilis and chancroid are very uncommon causes of GUD, all GUD cases are managed as probable genital herpes. ${ }^{82}$ In Cambodia, guidelines also have specific recommendations for probable herpes cases assessed on a clinical basis. ${ }^{83}$ Clearly, issues around overtreatment of STI and GUD as part of the syndromic approach in countries with scarce resources present a dilemma. Although overtreatment is acknowledged and unavoidable in syndromic management, the numbers of cases that receive unnecessary treatment which is acceptable to budget holders merit closer economic scrutiny.

Further adjustment of GUD algorithms will need to be made in areas with a high prevalence of HIV where delayed healing of ulcers is likely to become an increasing problem. While most cases of GUD caused by syphilis and chancroid usually respond to recommended treatments as anticipated, genital herpes has been identified as both the main cause of treatment failure in Malawi $^{84}$ and the likely cause of increased ulcer severity and chronicity seen in HIV positive patients compared with HIV negative patients in Nairobi. ${ }^{85}$

Ideally, every country with significant GUD prevalences should develop and evaluate its own algorithms under local conditions. Up until now, guidelines have been drawn up with an emphasis on simplicity so that one universal algorithm can cover one STI syndrome. 
Although policymakers have seemed reluctant to involve those actually involved in STI case management, it is clear that local experts must be consulted so that adaptations can be made which are suitable for use at the country, or even the provincial, level.

\section{COUNSELLING}

Although the WHO recommends that STI case management be provided at the primary healthcare level there are many obstacles in implementing this policy. In the absence of affordable antiviral therapy for HSV, if STIs and genital herpes to be dealt with adequately at the primary healthcare level, the issue of acquiring health education and counselling skills must be addressed in training workshops for STI service providers. The content of the training curriculum will require consideration of the many myths that have grown up around herpes and how they are perceived in communities. Where STIs are seen as a curse or punishment, providing a plausible explanation for an STI liable to recur and for which treatment is not available will be difficult. Issues over herpes transmission and the likelihood of recurrences are still surrounded by uncertainty, as are the best ways of discussing these points with patients. ${ }^{86}$ However, given the potential importance of HSV in facilitating HIV transmission, guidelines that could be used in a variety of settings must be drawn up and evaluated as a priority. The new WHO recommendations are awaited keenly particularly if they can be adapted readily for use in countries with STI problems that differ widely.

Where there are shortages of staff with STI knowledge and expertise, STI clinic staff should be utilised and encouraged to participate in STI training programmes which should include a genital herpes component. These STI service providers are already used to seeing significant numbers of cases, know their patient group, and are experienced in how best to reassure clients. They will also be able to explain how the problem can best be dealt with in a sensitive, non-judgmental manner appropriate to the particular culture of the individual.

Counselling about HSV should also be viewed as an opportunity to discuss HIV and HIV testing. Patients with HSV are at increased risk of $\mathrm{HIV}^{57}$ and in many cases may be HIV infected already. As voluntary testing and counselling become more acceptable in communities, there is a real potential for skills learnt in counselling for HSV to be applied for HIV and vice versa.

Counselling and health education for HSV are likely to be the most effective options in the management of HSV for some time. Although the cost of aciclovir has reduced considerably in developed countries, pricing in developing country settings remains prohibitively high. To have a significant impact on the prevalence of HSV-2, aciclovir use would have to be widespread and sustained. ${ }^{87}$ If the cost of aciclovir were to be reduced further, its use should perhaps be considered in core groups at high risk for HIV infection but not as a substi- tute for condoms. Donors should be lobbied about providing funds so that, at the very least, those with genital herpes lesions as a consequence of advanced immunodeficiency can have access to anti-herpes medication.

\section{Conclusions}

HSV appears to be increasing significantly in developing countries. This has important implications for the spread of HIV because of the facilitatory effect of GUD on HIV transmission.

Algorithms for GUD have changed little over the years since the HIV epidemic became established and must take into account the increased prevalence of HSV now and the likelihood that it will increase in the future. In countries where syphilis and chancroid are still prevalent, it would still be reasonable to treat all new cases of genital ulceration for syphilis and chancroid. Those with recurrences should be interviewed and asked about previous episodes of ulceration typical of herpes. Such cases would not be treated for syphilis and chancroid but would be counselled about herpes and asked to return.

The increasing incidence of genital herpes is part of a rapidly changing profile of STI epidemiology in developing countries. Putting STI surveillance systems in place will be crucial in monitoring such changes so that appropriate adjustments can be made to treatment schedules to make them more cost effective. Strong consideration should be given to supporting STI surveillance for GUD in areas with high prevalences of HIV. While this support has been sadly neglected in the past, policymakers now need to be targeted so that further opportunities to limit the spread of HIV, in particular by decreasing the incidence of GUD and genital herpes, are not missed.

1 Fleming DT, Wasserheit JN. From epidemiological synergy to public health policy and practice: the contribution of other sexually transmitted diseases to sexual transmission of HIV infection. Sex Transm Inf 1999;75:3-17.

2 Royce RA, Sena A, Cates W, et al. Sexual transmission of Royce RA, Sena A, Cates W, et al. Sexur

3 Cameron DW, Simonsen JN, D'Costa LJ, et al. Female to male transmission of human immunodeficiency virus type 1: risk factors for seroconversion in men. Lancet 1989;ii: 403-7.

4 Mehendale SM, Rodrigues JJ, Brookmeyer RS. Incidence and predictors of human immunodeficiency virus type 1 seroconversion in patients attending sexually transmitted disease clinics in India. 7 Infect Dis 1995;172:1486-91.

5 Hayes RJ, Schulz KF, Plummer FA. The cofactor effect of genital ulcers on the per-exposure risk of HIV transmission in sub-Saharan Africa. $\mathcal{F}$ Trop Med Hyg 1995;98:1-8.

6 O'Farrell N, Hoosen AA, Coetzee K, et al. Genital ulcer disease in men in Durban, South Africa. Genitourin Med 1991;67:327-30.

7 O'Farrell N, Hoosen AA, Coetzee K, et al. Genital ulcer disease in women in Durban, South Africa. Genitourin Med 1991;67:322-6.

8 Katzenstein DA, Latif A, Bassett MT, et al. Risks for heterosexual transmission of HIV in Zimbabwe. Third International Conference on AIDS. Washington 1987 Abstract M.8.3

9 O'Farrell N, Windsor I, Becker P. Risk factors for HIV-1 in attenders at a sexually transmitted diseases clinic in Durban, South Africa. Sixth International AIDS Conference, June 1990, San Francisco. (Abstract FC 604.)

10 Nzila N, Laga M, Thiam MA, et al. HIV and other sexually transmitted diseases among female prostitutes in Kinshasa. AIDS 1991;5:715-21.

11 Osoba AO, Iyun A. Herpes genitalis in Ibadan. West Afr Med f 1970;19:117-19.

12 Rajan VS, Doraisingham M, Sng EH, et al. Polymicrobial aetiology of genital ulcers. Singapore Med $\mathcal{f}$ 1982;23:20713.

13 Thirumoorthy T, Sng EH, Doraisingham S, et al. Purulent penile ulcers of patients in Singapore. Genitourin Med 1986;62:253-5. 
14 Taylor DN, Duangmani C, Suvongse C, et al. The role of $\mathrm{H}$ ducreyi in penile ulcers in Bangkok. Sex Transm Dis 1984 11:148-51.

15 Jeyasingh P, Ramanaiah TB, Fernandes SD. Pattern of sexually transmitted disease in Madurai. Genitourin Med 1985;61:399-403.

16 Dangor Y, Fehler G, Exposto F, et al. Causes and treatment of sexually acquired genital ulceration in southern Africa. South Afr Med F 1989;76:339-41.

17 Nsanze H, Fast MV, D'Costa LJ, et al. Genital ulcers in Kenya. Clinical and laboratory study. Br f Vener Dis 1981; 57:378-81.

18 Crewe Brown HH, Krige FK, Davel GH, et al. Genital ulceration in males at Ga-Rankuwa Hospital, Pretoria. South Afr Med F 1982;62:861-3.

19 Coovadia YM, Kharsany AB, Hoosen AA.The microbial aetiology of genital ulcers in black men in Durban. Genitourin Med 1985;61:266-9.

20 Duncan MO, Bilgeri YR, Fehler HG, et al. The diagnosis of sexually acquired genital infections in black patients in Johannesburg, South Africa. South Afr $\mathcal{F}$ Sex Transm Di 1981;1:20-3

21 Mabey DC, Wall RA, Bello CS. Aetiology of genital ulceration in the Gambia. Genitourin Med 1987;63:312-15.

22 Meheus A, Van Dyck E, Ursi JP, et al. Etiology of genital ulcerations in Swaziland. Sex Transm Dis 1982;10:33-5.

23 Plummer FA, D'Costa LJ, Nsanze H, et al. Clinical and microbiological studies of genital ulcers in Kenyan women. Sex Transm Dis 1985;12:193-7.

24 Duncan MO, Ballard RC, Bilgeri YR, et al. Sexually transmitted genital infections in urban black women. South Afr F Sex Transm Dis 1984;4:23-7.

25 Medical Officer of Health for Harare. Annual report, 1982.

26 Medical Officer of Health for Durban. Annual report, 1989.

27 Nahmias AJ, Lee FK, Beckman-Nahmias S. Seroepidemiological and sociological patterns of herpes simplex virus infection in the world. Scand F Infect Dis 1990;69(Suppl): 19-36.

28 Schomogyi M, Wald A, Corey L. Herpes simplex virus-2 infection. An emerging disease? Infect Dis Clin N Am 1998; 12:47-61.

29 Hazlett DT, Bowmer MI, Nsanze H, et al. Herpes simplex in clinically suspected chancroid in Nairobi, Kenya. Afr $\mathcal{F}$ Sex Transm Dis 1984:1:16-18.

30 Hanenberg RS, Rojanapithayakorn W, Kunasol P, et al. Impact of Thailand's HIV control programme as indicated by the decline of sexually transmitted diseases. Lancet 1994;344:243-5.

31 Chua SH, Cheong WK. Genital ulcer disease in patient attending a public health clinic in Singapore: an epidemiologic study. An Acad Med Singapore 1995;24:510-14.

32 Zainah S, Sinniah M, Cheong YM, et al. A microbiological study of genital ulcers in Kuala Lumpur. Med 7 Malaysia 1991;46:274-82.

33 Hudson BJ, van der Mehden W, Lupiwa T, et al. A survey of sexually transmitted diseases in five STD clinics in Papua New Guinea. PNG Med f 1994;37:152-60.

34 O'Farrell N, Tovey SJ. High cumulative incidence of genital herpes amongst HIV -1 seropositive heterosexuals in south herpes amongst HIV -1 seropositive heter

35 Bogaerts J, Ricart CA, Van Dyck E, et al. The aetiology of genital ulceration in Rwanda. Sex Transm Dis 1989;16:123 6.

36 Kamya M, Nsubuga P, Grant RM, et al. The high prevalence of genital herpes among patients with genital ulcer disease in Uganda. Sex Transm Dis 1995;22:351-4.

37 Moffat H, Rahman M, Ballard R, et al. The aetiology of sexually transmitted diseases in Botswana. Tenth International Conference on AIDS, Yokohama, Japan 1994, Abstract 413C

38 Medical Officer of Health for Harare. Annual Report 1990.

39 Medical Officer of Health for Harare. Annual Report 1998.

40 Obasi A, Mosha F, Quigley M, et al. Antibody to herpes Obasi A, Mosha F, Quigley M, et al. Antibody to herpes
simplex virus type 2 as a marker of sexual risk behaviour in rural Tanzania. $f$ Infect Dis 1999;179:16-24.

41 Kamali A, Nunn AJ, Mulder DW, et al. Seroprevalence and incidence of genital ulcer disease in a rural Ugandan population. Sex Transm Inf 1999;75:98-102.

42 Dada AJ, Ajayi AO, Diamondstone L, et al. A serosurvey of Haemophilus ducreyi, syphilis, and herpes simplex virus type 2 infection and their association with human immunodeficiency virus among female sex workers in Lagos, Nigeria. Sex Transm Dis 1998;25:237-42.

43 Nelson K, Eiumtrakul S, Celantano D, et al. The association of herpes simplex virus type 2 (HSV2), Haemophilus ducreyi, and syphilis with HIV infection in young men in northern Thailand. F AIDS 1997;16:293-300.

44 Fleming DT, McQuillan GM, Johnson RE, et al. Herpes simplex type 2 in the United States, 1976-1994. N Engl $f$ Med 1997;3337:1105-11

45 Conde-Glez CJ, Juarez-Figueroa L, Uribe-Salas F, et al. Analysis of herpes simplex virus 1 and 2 infection in women with high risk sexual behaviour in Mexico. Int $\mathcal{F}$ Epidemio 1999;28:571-6.

46 Carvalho M, de Carvalho S, Pannuti CS, et al. Prevalence of herpes simplex type 2 antibodies and a clinical history of herpes in three different populations in Campinas City, Brazil. Int $\mathcal{F}$ Infect Dis 1999;3:94-8.

47 Oberle MW, Rosero- Bixby L, Lee FK, et al. Herpes simplex virus type 2 antibodies:high prevalence in monogamous virus type 2 antibodies:high prevalence in monogamous
women in Costa Rica. Am f Trop Med Hyg 1989;41:224-8.

48 Morse SA, Trees DL, Htun Y, et al. Comparison of clinical diagnosis and standard laboratory and molecular methods for the diagnosis of genital ulcer disease in Lesotho: associ- ation with human immunodeficiency virus infection. $\mathcal{F}$ Infect Dis 1997;175:583-9.

49 Wawer MJ, Sewankambo NK, Serwadda D, et al. Control of sexually transmitted diseases for AIDS prevention in Uganda: a randomised community trial. Lancet 1999;353: 525-35.

50 Morse S, Chen CY, Htun Y, et al. Molecular approaches to the diagnosis of genital ulcer disease in South Africa. Abstract O180. 12th Meeting of the ISSTDR. Seville, Abstract O180. 12th $M$

51 Van Dyck E, Koblavi SA, Ghys PD, et al. Diagnosis of genital ulcers in female sex workers by multiplex PCR and in vitro antibiotic susceptibility of $\mathrm{H}$ ducreyi strains in Abidjan, Cote D'Ivoire. Abstract P362. 12th Meeting of the ISSTDR. Seville, Spain 19-22 Oct 1997.

52 Risbud A, Chan-Tack K, Gadkari D, et al . The aetiology of genital ulcer diseases by multiplex polymerase chain reaction and relationship to HIV infection among patients attending sexually transmitted disease clinics in Pune, India. Sex Transm Dis 1999;26:55-62.

53 Beyrer C, Jitwatcharanan K, Natpratan C, et al. Molecular methods for the diagnosis of genital ulcer disease in a sexually transmitted disease clinic population in Northern Thailand: predominance of herpes simplex virus infection. f Infect Dis 1998;178:243-6.

54 Leng HB, Vathiny OV, Berlioz-Arthaud A, et al. Fuelling the fire - sexually transmitted infections in Cambodia: prevalence, antibiotic susceptibilities and WHO algorithm performance. Fourth International Conference on AIDS in Asia and the Pacific, Manila, Philippines, Oct 1997.

55 Behets, FM, Braithwaite AR, Hylton-Kong T, et al. Genital ulcers: etiology, clinical diagnosis, and associated human immunodeficiency virus infection in Kingston, Jamaica. Clin Infect Dis 1999;28:1086-90.

56 Rompalo A, Shepherd M, Lawlor JP, et al. Definitions of genital ulcer disease and variation in risk for prevalent human immunodeficiency virus infection. Sex Transm Dis 1997:24:436-42.

57 Dickerson $\mathrm{M}$, Johnstone J, Delea TE, et al. The causal role for genital ulcer disease as a risk factor for transmission of human immunodeficiency virus. Sex Transm Dis 1996;23. human im 429 .

58 Gwanzura L, McFarland W, D’Anna A, et al. Association between human immunodeficiency virus and herpes simplex virus type 2 seropositivity among male factory workers in Zimbabwe. F Infect Dis 1998;177:481-4.

59 Langeland N, Haarr L, Mhalu F. Prevalence of HSV-2 antibodies among STD clinic patients in Tanzania. Int $\mathcal{F} S T D$ AIDS 1998;9:104-7.

60 Dobbins JG, Mastro T, Nopkesorn T, et al. Herpes in the time of AIDS: a comparison of the epidemiology of HIV-1 and HSV-2 in young men in northern Thailand Sex Transm Dis 1999;26:68-74.

61 Wagner HU, Van Dyck E, Roggen E, et al. Seroprevalence and incidence of sexually transmitted diseases in a rura Ugandan population. Int $\mathcal{F}$ STD AIDS 1994;5:322-37.

62 Goh CL. Epidemiology of sexually transmitted diseases in Singapore, 1977-1993. Ann Acad Med Singapore 1995;24: 495-9.

63 Kumar B, Rajagopolan M. Rising incidence of genital herpes in an STD clinic in North India. Genitourin Med 1991;67:353-4.

64 Medical Officer of Health for Harare. Annual report, 1993. 65 Medical Officer of Health for Harare. Annual report, 1997. 66 Medical Officer of Health for Durban. Annual report, 1994.

67 Medical Officer of Health for Durban. Annual report, 1997.

68 Kharsany AB, Mahabeer Y, Goga R, et al. Aetiology of genital ulcer disease and HIV infection among men attending a STD clinic. Abstract 533. Thirteenth Meeting of the ISSTDR, July 11-14, 1999, Denver, Colorado.

69 Department of Health, RSA. Eighth National HIV survey of women attending antenatal clinics of the public services. Unpublished report, February 1999.

70 Htun Y, Dangor Y, Fehler G, et al. Temporal changes in the aetiology of genital ulcer disease among STD clinic attend-
ers in South Africa- the influence of concomitant HIV infection. Fifth Joint Confererence of the Sexually Transinfection. Fifth Joint Confererence of the Sexually Transmitted Diseases and Infectious Disease
Africa, Capetown, South Africa, 1997.

71 Bogaerts J, Kestens L, van Dyck E, et al. Genital ulcers in a primary health clinic in Rwanda:impact of HIV infection on diagnosis and ulcer healing (1986-1992). Int 7 STD AIDS 1998;9:706-10.

72 Adelusi B, Fabiyi A, Osunkoy BO. Seroepidemiology of type-2 (genital) herpes simplex virus infection in Ibadan. $f$ Hyg Epidemiol Microbiol Immunol 1978;22:453-9.

73 Braithwaite AR, Figueroa JP, Ward E. A comparison of prevalence rates of genital ulcers among persons attending
a sexually transmitted disease clinic in Jamaica. West Ind Med $\mathcal{f} 1997 ; 46: 67-71$.

74 World Health Organisation. Control of sexually transmitted diseases. Geneva: WHO, 1985.

75 World Health Organisation. Management of patients with sexually transmitted diseases. WHO Technical Report Series 810. Geneva: WHO, 1991.

76 Bogaerts J, Vuylsteke B, Tello WM, et al. Simple algorithms for the management of genital ulcers: evaluation in a primary health care centre in Kigali, Rwanda. Bull World Health Organ 1995;73:761-7.

77 World Health Organisation. Global programme on AIDS Management of sexually transmitted diseases. WHO/GPA TEM/94.1. Geneva: WHO, 1994. 
78 UNAIDS/WHO meeting report (draft). Advisory group meeting on sexually transmitted infections management. Geneva: WHO, 11-14 May 1999.

79 Htun Y, Morse S, Dangor Y, et al. Comparison of clincally directed disease specific, and syndromic protocols for the management of genital ulcer disease in Lesotho. Sex Transm Inf 1998;74(Supp1 1):S23-8.

80 Mayaud P, ka-Gina G, Cornelissen J, et al. Validation of a WHO algorithm with risk assessment for vaginal discharge in Mwanza, Tanzania. Sex Transm Inf 1998;74(Suppl 1):S77-84.

81 Langenberg A, Benedetti J, Jenkins J, et al. Development of clinically recognizable genital lesions among women previously identified as having asymptomatic herpes simplex virus type 2 infection. Ann Intern Med 1989;110: 882-7.

82 National AIDS/ STD prevention and control programme. Manual for training in care and prevention of sexually transmitted diseases. Republic of the Philippines: Department of Health, 1997
83 World Health Organisation. STD case management. The syndromic approach for primary health care settings. Cambodian version. Western Pacific Region: WHO, 1998

84 Behets FM, Liomba G, Lule G, et al. Sexually transmitted diseases and Human Immunodeficiency virus control in Malawi: a field study of genital ulcer disease. $\mathcal{F}$ Infect Dis 1995;171:451-5.

85 Kimani J, Bwayo JJ, Anzal AO, et al. Low dose erythromycin regimen for the treatment of chancroid. E Afr Med $\mathcal{F} 1995$ 72:645-8.

86 Barton SE, Munday PE, Patel RJ. Asymptomatic shedding of herpes simplex virus from the genital tract: uncertainty and its consequences for patient management. Int 7 STD AIDS 1996;7:229-32

87 White PJ, Garnett GP. Use of antiviral treatment and prophylaxis is unlikely to have a major impact on the prevalence of herpes simplex virus type 2. Sex Transm Inf 1999; 75:49-54. 